\title{
The Harvest of Tsam-Tsam in a Congolese Bowl: Body Adaptations of Harvesters
}

\author{
Yvon Rock Ghislain Alongo ${ }^{1,2 *}$, Simplice Innocent Moussouami1,2, Jean Georges André Moulongo ${ }^{1,2}$ \\ ${ }^{1}$ Laboratory of Effort Physiology and Biomechanics, Marien Ngouabi University, Brazzaville, The Republic of the Congo \\ ${ }^{2}$ Higher Institute of Physical and Sports Education (ISEPS), Marien Ngouabi University, Brazzaville, The Republic of the Congo \\ Email: *alongoyvonrock@gmail.com
}

How to cite this paper: Alongo, Y. R. G., Moussouami, S. I., \& Moulongo, J. G. A. (2020). The Harvest of Tsam-Tsam in a Congolese Bowl: Body Adaptations of Harvesters. Advances in Physical Education, 10, 106-113.

https://doi.org/10.4236/ape.2020.102010

Received: March 4, 2020

Accepted: May 8, 2020

Published: May 11, 2020

Copyright $\odot 2020$ by author(s) and Scientific Research Publishing Inc. This work is licensed under the Creative Commons Attribution-NonCommercial International License (CC BY-NC 4.0). http://creativecommons.org/licenses/by-nc/4.0/ (c) (i) (3) Open Access

\begin{abstract}
This exploratory and diagnostic standard study on the harvesters of local wine made from date palm aims to assess the effects of the practice of harvesting tsam-tsam, on the arch of the palm and thickening-hardening of the palm in the tsam-tsam harvesters in the marshy environment of the Congolese forest basin. This experimental, longitudinal, analytical and comparative study, exclusively concerned only the harvesters of swampy and non-swampy areas. Out of a population of 85 harvesters from different villages, 55 harvesters from villages in the districts of Makoua and Owando in the northern part of the country were chosen. It took place in the period of July 15, 2018 and July 19, 2019. The non-probabilistic method and the reasoned sampling technique were used for the choice of subjects. The subjects were randomized into two groups: a first experimental group ( $\mathrm{GE}=25$ ) operating in the marshy area, a second control group $(\mathrm{GC}=30)$ in the non-marshy area. The kinesiology technique based on the podoscope to be scanned with a manual platform made it possible to appreciate the effect of the marshy environment on deformations of the arch of the palm of the hand of tsam-tsam harvesters. The results showed that the values of the arch of the hands are significantly higher in the tsam-tsam harvesters living in the swampy area than those in the non-swampy area. The mercantile activity of the harvest of the local drink based on the sap of the date palm, helps fight poverty, and generates various deformations in the arch of the feet, from the hands of practitioners.
\end{abstract}

\section{Keywords}

Tsam-Tsam, Body Adaptations, Swampy Areas, Congo

\section{Introduction}

There are various activities allowing people to take care of themselves. Among 
these is the harvest of a local drink made from the date palm sap, known in the local language of northern Congo tsam-tsam. This mercantile activity is found in the marshy area of the Cuvette and practiced by the active layer of adults (20 - 60 years). It makes it possible to fight against poverty for a good number of populations. These activities, like any activity, generate energy expenditure and cause bodily, and motor adaptations in relation to the environment. A study by Brigaud (2015) stressed the importance of the skin afferents of the arch of the foot in the control of the specific aspects of rapid "stepping" compensatory reactions, evoked by unpredictable multidirectional postural disturbances in the four directions: translations towards the forward, backward, right or left, obeying the existence of three different accelerations (slow, medium, fast). Other work has focused on adults practicing rice or rice farming (Hatton et al., 2009; Vendel \& Roll, 1982). These works reveal that the foot is a very advanced anatomical structure, supporting the weight of the body and putting it in motion while adapting to various terrains during walking. Reaching all or part of this precision mechanics automatically disrupts the static and the support. In common trauma, the lesions encountered are most often benign, particularly if they concern the forefoot. However, these lesions, when they go unnoticed, can have disabling functional consequences. Serious lesions, rare, result from trauma with high kinetic energy. From these studies, it has been noted that hard soil deteriorates the foot. Long distance travel seems excessive and only reaches the limit of survival. In addition, observations made on the populations of the region of the marshy areas of the Congolese basin during the purchase of shoes during the funeral in Brazzaville highlight in the latter the absence of a number corresponding to the size of the foot. It is in this context that we conducted this study on "the harvesting of tsam-tsam in the Congolese Basin: body adaptations" with the question of research: what are the body adaptations induced by this practice or this activity? To answer this question, we formulate the following hypothesis: the harvest of tsam-tsam in the marshy environment of the Congolese forest basin induces bodily adaptations of the hand and the arch of the foot, noted at the level of the inter-phalangeal joints and translated by an increase in the tension of the ligaments and associated tendons. The objective assigned to this study is to determine the anatomical dimensions of the foot and the active and passive hand apple of the tsam-tsam harvesters in the marshy and non-marshy area. The interest of this work is to identify the risks encountered by the tsam-tsam harvesters in the practice of their activities, especially when they exercise barefoot.

\section{Materials and Methods}

\subsection{Study Framework}

The experimental, observational and case-control study was carried out in Congo Brazzaville from July 15, 2018 and July 19, 2019. The work took place in the northern area of the basin, in the marshy part of Makoua-Owando, or are located villages Adiba, Moh1, Moh2, Kiambe, Oyongo, Ikonda and Ibongo and Okowe which constituted the study sites. This area is characterized by the abun- 
dance of date palms for the tsam tsam harvest.

\subsection{Participants}

The survey focused in this area on a population aged 19 to 65 years representing $95 \%$ of the active population of the Congo (CNSEE, 2015). The population is villager of eight aforementioned villages, having 256 subjects including 85 subjects gathering tsam-tsam. From the target population, we were able to retain the sampling, this was based on inclusion and exclusion criteria: beings collecting tsam-tsam, beings having from 1 to 3 months of activity, beings being punctual in activities during the 11 harvest months without interruption, otherwise we are excluded, being male.

The sample consisted of 55 tsam-tsam harvesters divided into two groups: 30 harvesters living in a non-swampy area (controls) and 25 harvesters living in a swampy area (case). All 55 harvesters operating for four years were subjected to foot and hand measurements.

\subsection{Experimental Protocol}

The surface stabilom parameters related to the length and the average position of the center of podal pressure (CPP) in the two anteroposterior and medial lateral axes were evaluated using an Aidex310S podoscope and a manual aluminum platform Linak CB9140AE with Foot CAD plantar scanner. 2D X8, this faster and more precise device. This plantar scanner allows us to perform a quick and very precise analysis of two feet and hands at the same time and to implement it automatically with software with new modes of action. Analysis time 8 seconds, Windows $8 / 10$ compatible. These measurements were taken at the beginning and at the end of the experiment.

\subsection{Variables Studied}

They consisted of the width of the toe (LPP), width of the arch of the foot (LVP) and width of the heel (LT), the thickness of the active hand (EMA), Thickness of the passive hand (EMP). This plantar scanner has a digital plant load analysis system, with the ability to archive images in the patient database and automatically measure foot and hand to compare images and thus support symmetries.

\subsection{Statistical Analysis}

The data was entered on epi Ifo Versio 5 - 1.0, then processed using SPSS 23.0 software. The quantitative variables were expressed as an arithmetic mean accompanied by the standard deviation. The comparison of two means for the continuous variables before and after the experiment was carried out by the paired Student's t-test to examine the effect of the shoe-wearing and glove program on each parameter of interest in tamm harvesters. For the comparison of the same variable between the pre and post harvesters, the Student's $t$ test for unpaired series was used. 


\section{Results}

The results shown in this Table 1 show that the populations have diversified socio-professional activities including higher scores in the practice of the activity of harvesting the tsam-tsam with $33.20 \%$, followed by the practice of hunting of $24.22 \%$, then $22.26 \%$ of fishermen and finally $20.31 \%$ ) of farmers.

The results show a highly significant difference before and after the practice of this activity on the sole dimension of the foot, namely the width of the tip of the toe in harvesters of the marshy environment (Table 2).

The results reveal that no notable difference was observed among the harvesters in non-swampy areas.

The results of Table 3 show a very significant difference between the harvesters of the marshy environment and those of the non-marshy environment in terms of the size of the width of the tiptoe. However, none was observed in for the rest of the parameters.

The results of this Table 4, show a very significant difference between the harvesters of the marshland environment and those of the non-marshland environment in terms of the dimension of the thickness of the active hand (EMA). However, none were observed in the thickness of the passive hand (EMP).

The results in Table 5 reveal that the measurements of the palms of active hands are significantly higher in harvesters from the forest and swamp environment. However, no difference was noted in the non-active palms.

Table 1. Sociodemographic characteristics of the populations of the different villages.

\begin{tabular}{cccccc}
\hline Villages & Harvesters & Hunters & Cultivators & Fishermen & $\begin{array}{c}\text { Total/Percentage } \\
(\%)\end{array}$ \\
\hline adiba & 8 & 7 & 2 & 6 & 23 \\
Moh 1 & 11 & 5 & 2 & 6 & 24 \\
Moh2 & 12 & 6 & 2 & 5 & 25 \\
Kiambe & 12 & 10 & 18 & 8 & 48 \\
Oyongo & 13 & 10 & 12 & 11 & 46 \\
Ikonda & 14 & 15 & 9 & 12 & 50 \\
Ibongo & 9 & 4 & 3 & 4 & 20 \\
Okowe & 6 & 5 & 4 & 5 & 20 \\
Total & $85(33.20 \%)$ & $62(24.22 \%)$ & $52(20.31 \%)$ & $57(22.26 \%)$ & $256(\%)$ \\
\hline
\end{tabular}

Table 2. Comparison of the measurements of the width of the tip of the feet (LPP), the width of the arch of the foot (LVP) and the width of the heel (LT) of the tsam-tsam harvesters in swampy environment.

\begin{tabular}{cccc}
\hline Foot dimensions & Before $(\mathrm{n}=25)$ & After $(\mathrm{n}=25)$ & $\boldsymbol{P}$ \\
\hline LPP $(\mathrm{cm})$ & $10.91 \pm 0.51$ & $11.87 \pm 0.29^{* * *}$ & $<0.001$ \\
LVP $(\mathrm{cm})$ & $9.50 \pm 0.71$ & $9.62 \pm 0.29$ & NS \\
L T $(\mathrm{cm})$ & $8.21 \pm 0.14$ & $8.53 \pm 0.45$ & NS
\end{tabular}

Abbreviations: NS: Not significant difference; ${ }^{* *}$ : Very significant difference $(p<0.01) ;{ }^{* * *}$ : Highly significant difference $(p<0.001)$. 
Table 3. Tiptoe width (LPP), arch width (LVP) and heel width (LT) in non-marshy areas for harvesters.

\begin{tabular}{cccc}
\hline Foot dimensions & Before $(\mathbf{n}=30)$ & After $(\mathbf{n}=30)$ & $P$ \\
\hline LPP $(\mathrm{cm})$ & $10.47 \pm 0.19^{* * *}$ & $10.60 \pm 0.42$ & NS \\
LVP $(\mathrm{cm})$ & $9.10 \pm 0.71$ & $9.10 \pm 0.29$ & NS \\
LT $(\mathrm{cm})$ & $8.54 \pm 0.14$ & $8.62 \pm 0.45$ & NS \\
\hline
\end{tabular}

Abbreviations: NS: Not significant difference; ${ }^{* *}$ : Highly significant difference $(p<0.001)$; LPP: tiptoe width; LVP: arch width; LT: heel width.

Table 4. Comparison of tiptoe width (LPP), arch width (LVP), heel width (LT) before and after harvest activity in harvesters from marshy and non-marshy areas.

\begin{tabular}{cccc}
\hline Foot Dimensions & Before & After & $\boldsymbol{P}$ \\
\hline "Swampy" harvesters & $(\mathrm{n}=25)$ & $(\mathrm{n}=25)$ & \\
LPP $(\mathrm{cm})$ & $10.09 \pm 0.51$ & $11.17 \pm 0.29^{* *}$ & $<0.01$ \\
LVP (cm) & $9.50 \pm 0.71$ & $9.52 \pm 0.29$ & NS \\
L T (cm) & $8.54 \pm 0.14$ & $8.53 \pm 0.45$ & NS \\
"Non-swampy" subjects & $(\mathrm{n}=30)$ & $(\mathrm{n}=30)$ & \\
LPP $(\mathrm{cm})$ & $10.07 \pm 0.49$ & $10.10 \pm 0.52$ & NS \\
LVP $(\mathrm{cm})$ & $9.50 \pm 0.71$ & $9.52 \pm 0.29$ & NS \\
LT $(\mathrm{cm})$ & $8.54 \pm 0.14$ & $8.54 \pm 0.45$ & NS \\
\hline
\end{tabular}

Abbreviations: NS: Not significant difference; ${ }^{* *}$ : Very significant difference $(p<0.01)$; ${ }^{* *}$ : Highly significant difference $(p<0.001)$; LPP: tiptoe width; LVP: arch width; LT: heel width.

Table 5. Thickness of the active hand (EMA) and thickness of the passive hand (EMP) after the experiment between harvesters from swampy and non-swampy environments.

\begin{tabular}{cccc}
\hline Hand dimensions & GC $(\mathrm{n}=30)$ & GE $(\mathrm{n}=25)$ & $p$ \\
\hline EMA $(\mathrm{cm})$ & $4.12 \pm 0.61$ & $5.75 \pm 0.02^{* * *}$ & $<0.001$ \\
EMP $(\mathrm{cm})$ & $4.11 \pm 0.62$ & $4.51 \pm 0.29$ & NS \\
\hline
\end{tabular}

Abbreviations: NS: Not significant difference; ${ }^{* *}$ : Significant difference $(p<0.001)$; EMA: Thickness of the active hand and EMP: Thickness of the passive hand.

\section{Discussion}

The aim of the study was to assess the effects induced by the harvesting of tsam-tsam in swampy and forested areas on podal and manual characteristics. The results obtained show that the deformations at the level of the foot are not dependent on the typology of feet, whatever the Greek or Egyptian foot. Plantar skin sensitivity translates the interface between the body and the soil otherwise the support or surface contact with the ground. The pressure, the speed, of acceleration and directional stretching, have a role of true platform of force able to inform the system of equilibration on the static and dynamic parameters of the three-dimensional forces brought into play at the interface. 


\section{Limit of the Study}

Some limits deserve to be underlined in this study: This longitudinal type study presents only a single snapshot of the phenomenon studied, particularly in deformities of the feet and hands, which may or may not give reliable results. In addition, the nature of these deformities may be other factors such as the frequency of activity has not been specified by practitioners due to the lack of medical follow-up. This work should be extended to all areas of activity practice for a larger sample.

According to Cardetti (2014), the dimensions are assessed by scanner or MRI, in landfill. This induces approximation of interpretation and projection bias. Stereoradiography and the methods of reconstruction of associated 3D models have proven their interest as an alternative, concerning the lower limbs and the spine. The extension of the use of this technique for the foot involves difficulties, in particular related to growth due to incomplete ossification or our series of people are already adult and are found in the great forest of the Congolese quagmire.

In relation to the results, it seems likely that the marshy environment has an influence on the deformations of the osteoarticular system of the foot. Similarly, Bishop, Fiolkowski, Conrad et al. (2005) demonstrate in a study that a runner with shoes ends up with an ankle dorsiflexion increased by 12 degrees compared to barefoot runners. However, Bruggemenn, Potthast, Braustien et al. (2005) finds values increased by 7 to 10 degrees between barefoot runners and those wearing shoes. Our observations are similar to those of these authors. Our subjects have an ankle dorsiflexion angle increased by 10 degrees when wearing. This represents a gain of $9.11 \%$. This justifies the tiptoe deviations in swampy environment to develop the base of support of the ground supports with a load. Furthermore, Besse et al. (2005) report that the foot, like other parts of the body, accumulates suffering. They are essential for vascular, osteoarticular, cutaneous, tendinomuscular or neurogenic origin, whatever the lesion, the foot must benefit from specific treatments, podiatric therapies: standard shoes, therapeutic or not, custom shoes, plantar orthotics, orthotics toes. Compared to our series of mechanical actions, they deserve to be better known and more prescribed, their actions being irreplaceable in many pathologies of the senior foot. Other times, more than $90 \%$ of our subjects change their support depending on the load and the slippery terrain as also observed (Brigaud, 2011). All of the subjects in our study are harvesters who have always traveled in open conditions. Our study joins Brigaud's conclusions (Brigaud, 2013; Rampal et al., 2017) which show that the type of footwear changes the support pose. However, another study by the same author observed during a marathon that the $90 \%$ of runners who attacked forefoot and the $60 \%$ of midfoot runners changed their pose to attack by the heel during the passage to the $32^{\text {nd }}$ kilometer compared to their passage at the $10^{\text {th }}$ kilometer. This also depends on load because our subjects in the presence of slippery terrain and having mud, the inter metatarsal joints move apart to in- 
crease the contact surfaces as a basis for support. The work of Largey, Subsol, Micallet, Cyteval, Barrault, Canovas, Chemouny, Banegas, \& Bonnel (2007) reveals that the specific metatarsal mobilities in the three axes of work showed displacements in adduction, supination and dorsal flexion for the lateral metatarsals, and in adduction, supination and plantar flexion for the medial metatarsals. These results express the reality of tarsometatarsal mobility, and establish a new basis for reflection for surgical therapies and forefoot modeling. On the other hand, Altman \& Davis (2012) demonstrate that runners continue to run on the heel while being barefoot, $80 \%$ of the subjects in the "control" group spontaneously changed their support pose either by running on the forefoot or the mid-foot. On the other hand, $20 \%$ of the "control" group kept the same support pose during the passage barefoot. We might wonder if a longer adaptation time would be necessary to observe a change in their support phase. However, our series, the harvesters in loads to move whose body is presented as the resulting force

\section{Conclusion}

Our study allowed us to assess the repercussions of a load conditioned by tsam-tsam harvesting activities on the metatarsal osteoarticular chain of the arch harvester in a wooded and marshy area of northern Congo Brazzaville. Regarding the anatomical location of the trauma, the results are important for the proper management of linked health capital physical activity. In order to be able to improve performance and reduce cases deformation of the arch and palms of Congolese tsam-tsam harvesters, it is important that this tsam-tsam harvesting activity in forest and swampy areas; harvesters must use appropriate footwear with gloves suitable for the activist.

\section{Conflicts of Interest}

The authors declare no conflicts of interest regarding the publication of this paper.

\section{References}

Altman, A. R., \& Davis, I. S. (2012). Barefoot Running Biomechanics and Implications for Running Injuries. Current Sports Medicine Reports, 11, 244-250. https://doi.org/10.1249/JSR.0b013e31826c9bb9

Besse, J. L., Maestro, M., \& Ragusa, M. (2005). Radiographies standard et pathologies de l'avant-pied. In B. Valtin, \& T. Leemrijse (Eds.), Chirurgie de l'avant-pied (pp. 112-125). Paris: Elsevier SAS.

Bishop, M., Fiolkowski, P., Conrad, B. et al. (2005). Athletic Footwear, Leg Stiffness, and Running Kinematics. Journal of Athletic Training, 41, 387.

Brigaud, F. (2011). La marche et la performance sportive: Optimisation de la marche, de la course, du saut (128 p.). Ap: Ditions Désiris.

Brigaud, F. (2013). Course à pied, posture biomécanique, performance (176 p.). Ap: éditions. Désiris. 
Brigaud, F. (2015). Guide de la foulée avec prise d'appui avant-pied (96 p.). Ap: Éditions. Désiris.

Bruggemenn, G.-P., Potthast, W., Braustien, B. et al. (2005). Effect of Increased Mechanical Stimuli on Foot Muscles Functional Capacity. Proceedings of the International Society of Biomechanics 20th Congress, Cleveland, 31 July-5 August 2005, 553.

Cardetti, M. (2014). Influence du chaussage sur mes caractéristiques Biomécaniques de Course à pied et sur activité Électrique de deux muscles: Tibial Antérieur et le soléaire. Bordeaux: IFMK Bordeaux.

CNSEE (2015). Les statistiques du Centre National des statistiques et des études économiques, Brazzaville, République du Congo.

Hatton, A. L., Dixon, J., Martin, D., \& Rome, K. (2009). The Effect of Textured Surfaces on Postural Stability and Lower Limb Muscle Activity. Journal of Electromyography and Kinesiology, 19, 957-964. https://doi.org/10.1016/j.jelekin.2008.04.012

Largey, A., Subsol, G., Micallet, J. P., Cyteval, C., Barrault, J. J., Canovas, F., Chemouny, F., Banegas, S., \& Bonnel, F. (2007). Analyse tridimensionnelle de la mobilité des métatarsiens lors de la mise en charge du pied. Médecine et Chirurgie du Pied, 23, 9-16. https://doi.org/10.1007/s10243-007-0108-5

Rampal, V., Rebekah, S., Rohan, P. Y., Wicart, P., \& Skalli, W. (2017). 3D Modelisation of Children' Foot: Reproducibility and Reference Values of Parameters. Revue de Chirurgie Orthopédique et Traumatologique, 103, S33. https://doi.org/10.1016/j.rcot.2017.09.029

Vendel, J. P., \& Roll, J. P. (1982). Response to Pressure and Vibration of Slowly Adapting Cutaneous Mechanoreceptors in the Human Foot. Neuroscience Letters, 34, 289-294. https://doi.org/10.1016/0304-3940(82)90190-2 